\title{
MULHER, ESCOLARIZAÇÃO E TENDÊNCIAS EM CURSO
}

\author{
MUJER, ESCOLARIZACIÓN Y TENDENCIAS ACTUALES
}

\author{
WOMAN, EDUCATION, AND ONGOING TREND
}

DOI: https://doi.org/10.9771/gmed.v13i3.46118

\author{
Ana Cristina Furtado Pereira ${ }^{1}$ \\ Neide de Almeida Lança Galvão Favaro² \\ Priscila Semzezem ${ }^{3}$
}

Resumo: Este estudo, de natureza qualitativa, por intermédio de uma pesquisa bibliográfica, objetiva analisar o processo histórico de acesso da mulher à escolarização, especialmente ao Ensino Superior no Brasil, levando em conta suas contradições e as tendências em curso. Constata-se que o acesso feminino à escolarização e ao Ensino Superior esteve diretamente relacionado à expansão do capital e seus desdobramentos: urbanização, ingresso da mulher na exploração capitalista e conversão da educação em mercadoria. As desigualdades permanecem nas escolhas profissionais e nos rendimentos das mulheres, mas tendem a se reduzir. Preconiza-se que a luta pela emancipação feminina ultrapassa a questão identitária, demandando sua articulação com um projeto societal mais amplo.

Palavras-chave: História da educação. Trabalho e educação. Mulher. Ensino Superior.

Resumen: Ese estudio, de naturaleza cualitativa, por intermedio de investigación bibliográfica, tiene el objetivo de analizar el proceso histórico de acceso de la mujer hacia escolarización, especialmente la enseñanza superior en Brasil, teniendo sus contradicciones y tendencias actuales en cuenta. El acceso de la mujer hacia la escolarización y la enseñanza superior estuvo directamente relacionado con la expansión del capital y sus desdoblamientos: urbanización, entrada de las mujeres en la explotación capitalista y conversión de la educación en mercadoría. Las desigualdades persisten en las opciones profesionales y en los ingresos de las mujeres, pero tienden a reducir. Se recomienda que la lucha por la emancipación femenina vaya más allá del tema de la identidad, demandando su articulación con un proyecto societal más amplio.

Palabras clave: Historia de la educación. Trabajo y educación. Mujer. Enseñanza Superior.

Abstract: This is a qualitative study, and through bibliographical research, has as aim at analyzing the historical process of women's access to schooling, especially Higher education in Brazil, taking its contradictions and ongoing trends into account. Female access to schooling and to the higher education was directly related to the capital expansion and its outspread: urbanization, women's entry into capitalist exploitation and education conversion into merchandise. Inequalities remain in women's professional choices and earnings, but they tend to reduce. It is recommended that the struggle for female emancipation goes beyond the identity issue, demanding articulation with a broader society project.

Keywords: Education history. Work and education. Woman. Higher education.

\section{Introdução}

Pesquisas e dados recentes refletem a superioridade feminina no cenário educacional brasileiro. "Elas são, em grande parte, maioria entre estudantes e docentes, assim como lideram índices relacionados 
a cargos de gestão e à participação em avaliações” (INEP, 2021b, p. 1). Em relação aos resultados do Censo da Educação Superior de 2019, esse relatório constatou em levantamento específico que a taxa de permanência das mulheres é maior, sendo que, de 2010 a 2019, 43\% delas concluíram os cursos em que ingressaram, contra 35\% dos homens.

Em relação ao avanço das mulheres no Ensino Superior, especificamente, é importante analisar que desde os anos de 1991, conforme dados do Instituto Nacional de Estudos e Pesquisas Educacionais Anísio Teixeira (INEP), já se apontava a sua presença como maioria. "As mulheres não só representam a maior parte dos inscritos nos vestibulares como a maioria dos ingressantes no ensino superior e a maior parcela dos concluintes, tendo obtido mais sucesso acadêmico que os homens" (ÁVILA; PORTES, 2009, p. 94).

Por outro lado, o Departamento Intersindical de Estatística e Estudos Socioeconômicos (DIEESE) divulgou índices acerca das mulheres no mercado de trabalho, nos terceiros trimestres de 2019 e 2020, revelando que persiste a diferença de rendimentos entre elas e os homens. Isso se verifica “[...] principalmente para as mulheres negras, que em 2020, receberam, em média, $\mathrm{R} \$ 10,95$ e o homem negro R\$ 11,95. Entre os não negros, o rendimento era R\$18,15 para as mulheres e R\$20,79, para os homens” (DIEESE, 2021, p. 1). O estudo vai além, indicando os efeitos da pandemia do coronavírus no país.

Essa crise sanitária, econômica e social reforçou a distância salarial entre homens e mulheres, em 2020, elas seguiram ganhando menos, mesmo quando ocupavam cargos de gerência ou direção, para elas a hora paga foi de $\mathrm{R} \$ 32,35$ e para eles, de $\mathrm{R} \$ 45,83$ ou com a mesma escolaridade: elas ganhavam em média $\mathrm{R} \$ 3.910$ e eles, R\$ 4.913. (DIEESE, 2021, p. 1)

Apesar de significativos avanços femininos no campo educacional, esses índices retratam que ainda não há uma equiparação de rendimentos entre mulheres e homens, permanecendo desigualdades socioeconômicas. As conquistas educacionais, entretanto, apontam uma tendência histórica à maior qualificação e preparação da mulher para o trabalho, o que se torna um indício de que há condições latentes para futuras transformações.

Tendo em vista esse panorama social e educacional, constituído de forma não linear e nem simplista, pois resultou de imbricados fatores, delimita-se este estudo na questão da educação feminina. Salienta-se a importância de acompanhar o percurso histórico do acesso das mulheres à educação, pois considera-se que assim é possível revelar as diversas dificuldades enfrentadas para assegurarem seu direito ao ensino no Brasil, bem como a incidência determinante de fatores estruturais nessa trajetória. Na perspectiva do materialismo histórico, defende-se a necessidade de sua vinculação à totalidade histórica e social mais ampla, a fim de assegurar a apreensão desse fenômeno para além da sua aparência.

Nesse sentido, este estudo tem como objetivo analisar o processo histórico de acesso da mulher à escolarização, especialmente à Educação Superior no Brasil, considerando suas contradições e as tendências em curso. A análise qualitativa, pautada em estudos bibliográficos e em dados empíricos, auxilia a apreensão da realidade, permitindo captar tendências em curso e seus vínculos com a lógica do capital, condição imprescindível para subsidiar as lutas humanas pela igualdade social. 
Expõe-se inicialmente a história do acesso das mulheres à escolarização no Brasil, vinculando-a aos fatores socioeconômicos que subsidiaram esse processo. Analisa-se em seguida a sua presença atual no Ensino Superior, identificando seus desdobramentos, as suas causas e as possíveis tendências em curso.

\section{O acesso das mulheres à escolarização no Brasil e seus vínculos com o avanço do capital}

A questão socioeconômica permeia a história da educação, tanto dos homens quanto das mulheres. O Brasil foi marcado, desde sua colonização, por uma educação que era destinada a uma minoria da população, principalmente aos meninos das classes favorecidas. As condições de produção pautadas no trabalho escravo e na economia agroexportadora voltada à mercantilização portuguesa dispensavam a necessidade de estender a escolarização no país.

$\mathrm{O}$ vínculo estreito entre os interesses econômicos da metrópole e a educação colonial resultou no domínio dos jesuítas, que iniciaram a empreitada educacional desde o século XVI. Ribeiro (2003) revela uma distinção entre o plano de Manuel da Nóbrega, voltado aos indígenas e colonos, e a orientação da própria ordem jesuítica, que concentrava seu currículo em elementos da cultura europeia. De modo geral, os índios passaram a ser catequizados e os colonos instruídos nas escolas jesuíticas. "A educação feminina restringia-se a boas maneiras e prendas domésticas" (RIBEIRO, 2003, p. 24).

Essa afirmação, todavia, carece de caracterizações mais profundas, pois é necessário considerar que as mulheres trabalhadoras não tinham essa opção, visto que sua existência e educação eram determinadas pelo trabalho. Tendo em vista esses aspectos, denota-se a relevância de considerar a questão da mulher de modo amplo, observando suas próprias diversidades. Isso porque não é possível afirmar uma unidade de condições, mediante a posição social que ocupam na reprodução de suas vidas, seus valores e cultura, constituídos por povos de raças e etnias distintas. Uniformizar a condição das mulheres escravas e trabalhadoras com a situação daquelas que estavam liberadas dessa atividade por sua situação de classe, e que assim eram educadas para serem esposas e mães, seria um grave equívoco.

Permeada de viés religioso e humanista, a educação jesuítica se estendeu até 1759, quando se transferiu a educação para o Estado, a partir da reforma pombalina. Ela institui as aulas régias e permitiu que as mulheres frequentassem as aulas, desde que separadas por sexo. Também instituiu a possibilidade de a mulher atuar no magistério, mas apenas lecionando para as meninas. Pouco se alterou a situação real no âmbito da educação formal e pública, pois o acesso à escolarização feminina continuou restrito até o início do século XIX, quando nova preocupação com a educação da mulher se manifestou, a partir da independência de 1822 .

A Lei das Primeiras Letras, de 15 de outubro de 1827, determinou a criação de escolas de ensino elementar sob o dever do Estado, nas regiões mais populosas do país. Incluiu então escolas de meninas nas vilas e cidades, além de instituir remuneração igual aos professores e professoras, o que acabou não sendo aplicado na prática, pois havia diferenciação na formação exigida. Havia restrição da aritmética ensinada às meninas, não se admitia a coeducação e era proibido seu ingresso nos liceus, ginásios e academias (SILVA, 2002). 
Beltrão e Alves (2009) indicam que o ensino para as meninas devia ser ministrado por professoras, mas como o país não dispunha de muitas, acabou por não se atingir uma percentagem significativa. Foi na segunda metade do século XIX que houve uma relativa expansão de sua escolarização, mas com características de ensino definidas conforme o sexo. As mulheres que conseguiam estudar recebiam principalmente a educação primária, demarcada por conteúdos morais, voltados à sua atuação familiar e privada. A oferta de educação secundária abarcava os cursos normais, que as qualificavam para o ensino primário, atuais anos iniciais do ensino fundamental.

A partir de um projeto de lei de 1830 estabeleceu-se preferência ao magistério feminino para atuar no ensino primário. Mesmo assim, as primeiras escolas normais destinavam-se somente aos homens. “A primeira surgiu em Niterói (1835), seguida pelas da Bahia (1836), de Minas Gerais (1840), de São Paulo (1846) e do Rio de Janeiro (1880)" (SILVA, 2002, p. 83). Seu funcionamento era precário, acarretando em frequentes fechamentos e reaberturas.

Almeida (1998, p. 23) retrata a criação da primeira escola normal de São Paulo, em 1846, “[...] a princípio destinada ao sexo masculino e cujo ingresso era vedado às moças”. Foi somente em 1876, com o surgimento da sessão feminina da Escola Normal do Seminário da Glória, que foi possível à mulher profissionalizar-se no magistério.

Com o maciço ingresso feminino nessa escola, apesar da profissão de professora ter assumido contornos de maternidade e esculpir-se nos moldes da formação de boas donas de casa e mães de família, esse foi o primeiro passo dado pelas mulheres no período a fim de adquirir alguma instrução e conseguir o ingresso numa profissão. (ALMEIDA, 1998, p. 23)

O magistério foi assim uma das possíveis profissões destinada às mulheres e aceita pela sociedade daquele momento, por ter sido relacionada aos cuidados maternos. Já as demais profissões e o acesso ao Ensino Superior continuavam sendo vetados a elas. Nesse contexto identifica-se que ocorreram os primeiros passos em relação ao trabalho da mulher na educação de crianças menores, mesmo que reduzido ao cuidar, o que desqualificava a formação exigida e, portanto, o papel da mulher enquanto profissional de educação. Novamente, é importante destacar que:

Logicamente, isso estava restrito às mulheres das classes privilegiadas. Para as mulheres do povo, a ausência de instrução e o trabalho pela sobrevivência sempre foram uma dura realidade. $\mathrm{O}$ mesmo pode ser dito a respeito de raça e, para as mulheres negras, o estigma da escravidão perdurou por muito tempo, só lhes restando os trabalhos de nível inferior e a total ausência de instrução. (ALMEIDA, 1998, p. 35)

A educação da maioria das mulheres no período imperial continuou em uma situação de poucas possibilidades de instrução escolar, pois a expansão escolar no geral era bastante limitada, tendo em vista a manutenção de uma economia escravista e agroexportadora. Ademais, no Ensino Superior a situação era mais grave. "As mulheres foram excluídas dos primeiros cursos de Medicina (1808), Engenharia (1810) e Direito surgidos no país. O decreto imperial que facultou à mulher a matrícula em curso superior data de 1881” (BELTRÃO; ALVES, 2009, p. 128). A própria organização do ensino impossibilitava que a mulher chegasse ao nível superior, devido à impossibilidade de frequentar o Ensino Secundário. 
De qualquer forma, as mulheres achavam-se excluídas da possibilidade de acesso aos cursos superiores, mesmo que se preparassem adequadamente em escolas particulares ou com preceptores. Isso porque para tal não se exigiam diplomas, mas era necessário fazer os exames preparatórios aplicados pelo Colégio D. Pedro II, destinados exclusivamente ao público masculino. (ARANHA, 2006, p. 230)

Um elemento que persistia na sociedade brasileira dos séculos XIX e início do século XX, e até em culturas mais avançadas, é a concepção de inferioridade do intelecto feminino. $\mathrm{O}$ autor Robert Brifaut (apud PENA, 1981, p. 34-35), em 1927, afirmou na obra The Mothers que: "O poder crítico, analítico e criativo do intelecto está menos desenvolvido nas mulheres que nos homens". No Brasil, a influência do positivismo e das correntes higienistas nesse período repercutiram no conceito de mulher. "Educar passou a ser algo inerente à própria mulher, confundindo-se com uma qualidade da mesma” (SILVA, 2002, p. 86). Além disso, sob o “[...] pressuposto da inferioridade biológica e intelectual feminina [...]”, o positivismo do século XIX considerava “[...] natural o alicerçamento dos homens no poder, baseados na diferença natural entre os sexos" (ALMEIDA, 1998, p. 41).

Nesse contexto, Ritt (2012) identificou movimentos feministas no Brasil, por volta de 1870, influenciados por referenciais vindos do exterior, que defendiam a emancipação da mulher e sua inclusão no Ensino Superior. Destacou a Reforma Educacional de Leôncio de Carvalho, em 1879, que permitiu o ingresso das mulheres nos cursos superiores, embora isso tenha sido bastante restrito. Os debates sobre a coeducação também datam desse período e, conforme Almeida (1998, p. 56), “[...] em 1880, na inauguração da terceira Escola Normal na província de São Paulo, introduziram-se as aulas mistas”.

O contexto socioeconômico alterava-se no país, com a abolição do trabalho escravo e a instituição da República, no final do século XIX e início do século XX, impactando também na concepção de mulher e em sua educação. Tais alterações foram lentas e só se fizeram sentir mais intensamente a partir da década de 1930. "Até então, para além de algumas diretrizes de caráter geral, emanadas da esfera federal, o desenvolvimento e a provisão de educação dependeram das políticas dos governos em nível estadual" (NEVES; PRONKO, 2008, p. 32). Havia grandes disparidades regionais e elevadas taxas de analfabetismo no país. Em 1920 cerca de 70\% das pessoas com 15 anos ou mais eram analfabetas.

Um aspecto relevante a considerar nesse cenário é o avanço já existente na escolarização feminina brasileira, vindo do final do século XIX, que não pode ser ignorado. Ferraro (2010, p. 511) levantou dados de 1875 que indicam percentuais significativos de matrícula feminina em alguns estados, em relação ao número total: “[...] 44,4\% no Rio Grande do Sul, 37,9\% em São Paulo, 34,9\% no Pará, 29,1\% na Bahia, 21\% em Minas Gerais e 19\% no Amazonas (Almeida, 1989)". Ele constatou ainda que em Minas Gerais a matrícula feminina avançou de 21\% da matrícula total em 1875, para 34,4\% em 1889. Com base nos microdados do censo demográfico brasileiro do ano 2000, ele também registrou o início do processo de inversão da relação entre sexo e escolarização.

Tomemos a geração nascida até 1920, destacando, dentro desta, as pessoas nascidas entre 1906 e 1913, grupo que, no recenseamento 1920, contava de 7 a 14 anos. Pois bem, nesse grupo, em 1920, a taxa de alfabetização das meninas (19,35\%) já quase igualava a taxa dos meninos (20,2\%) (Brasil, 1920). Esses dados indicam com clareza que para se traçar e entender o movimento histórico de inversão na relação entre sexo e escolarização é necessário levar em conta que esse movimento ou tendência vem de 
longa data - pelo menos do início do século XX, provavelmente da segunda metade do século XIX. (FERRARO, 2010, p. 511)

Como se constata, esse período demarca um momento importante para a educação das mulheres brasileiras e é resultado de lutas e transformações que se davam no país, que eram direta e organicamente afetadas pelo cenário externo. O capital industrial se expandia a nível mundial e exigia a implantação do trabalho livre no Brasil, o que culminou no avanço das relações capitalistas.

É importante delimitar a influência do capital para a condição feminina em geral. A Revolução Industrial, iniciada na Inglaterra nas últimas décadas do século XVIII, impulsionou a utilização da força de trabalho das mulheres nas fábricas, local antes exclusivo aos homens, inserindo-as no processo de produção do mais-valor. Marx (1985) explicita de forma cristalina a revolução que a produção industrial provocou na família e na função das mulheres trabalhadoras, ao dispensar a necessidade de força muscular.

Crianças e mulheres foram expostas à “[...] degradação moral decorrente da exploração capitalista do trabalho [...]", e também à devastação intelectual, “[...] artificialmente produzida pela transformação de pessoas imaturas em meras máquinas de produção de mais-valia[...]” (MARX, 1985, p. 26), o que exigiu do Parlamento inglês condicionar o uso produtivo das crianças com menos de 14 anos à oferta de ensino primário. Demarca-se aqui também a relação entre o avanço do capital e a própria organização dos sistemas nacionais de ensino, que na Europa se consolidaram a partir da segunda metade do século XIX.

No caso das mulheres europeias, gradativamente sua subjetividade e a constituição da feminilidade eram transformadas, tendo em vista as próprias alterações estruturais da sociedade:

[...] a base material constitutiva da feminilidade como expressão do patriarcado, ou seja, a mulher maternal, passiva, com menos inclinação à sublimação cultural, infantilizada, que teria que ser propriedade de algum homem para acessar aos bens necessários a sua sobrevivência deixa de existir, ou, pelo menos, essas deixam de ser características vinculadas ao sexo feminino na medida em que as mulheres não se contentam mais com os limites dessa situação. Elas, agora, também podem ser ou proprietárias privadas dos meios de produção, ou proprietárias de sua força de trabalho. Por conseguinte, essa mulher que se 'contenta' com o cuidado do lar já não serve mais como espelho das insígnias identificatórias contra as quais as mulheres do séc. XIX se rebelaram, e, arriscamos afirmar, com as quais as mulheres do século XX ou XXI não têm mais nenhum tipo de possibilidade identificatória; são insígnias que nos parecem profundamente tradicionais. (CALADO, 2020, p. 126)

$\mathrm{Na}$ perspectiva teórico-metodológica aqui adotada, compreende-se que a consciência é produzida no âmbito da reprodução da existência humana, o que não depende da vontade individual dos sujeitos, sejam eles homens ou mulheres. "As ideias da classe dominante são, em cada época, as ideias dominantes, isto é, a classe que é a força material dominante da sociedade é, ao mesmo tempo, sua força espiritual dominante" (MARX; ENGELS, 2007, p. 47). Nesse sentido, a realidade historicamente constituída forja os sujeitos e suas identidades, nas relações sociais que contraem na vida em sociedade, não de forma atomizada e muito menos mecânica, pois suas subjetividades e ações concretas também abrem perspectivas de mudanças no processo coletivo de se fazer história. 
Coadunando com Calado (2020), compreende-se que a relação de produção tipicamente capitalista corroeu o patriarcado e suas formas de dominação tipicamente tradicionais, ao alterar a base material da sociedade, possibilitando à mulher a posse da propriedade privada dos meios de produção da vida ou a posse de sua força de trabalho. Isso não significa dizer que a opressão e a violência contra a mulher foram extintas, mas sim que as lutas atuais contra elas devem ser incisivas e levar em conta essa realidade e as possibilidades históricas concretas que se criaram a partir de então.

No caso do Brasil, a produção tipicamente industrial só avançaria mais efetivamente após a década de 1930, mas a urbanização e a constituição da força de trabalho livre, necessária para a exploração pelo capital industrial, já estavam em curso nas regiões mais desenvolvidas do país, de forma lenta, o que se revela nos índices escolares já apontados.

Esse contexto geral impactou na educação e no trabalho feminino, já nas primeiras décadas do século XX. No quesito do magistério primário, ele se revelava como ocupação essencialmente feminina, o que “[...] possibilitou às mulheres, notadamente da classe média que se alicerçava no panorama socioeconômico do país, a oportunidade para ingressar no mercado de trabalho" (ALMEIDA, 1998, p. 28).

Fatores conjunturais mundiais relacionados à expansão do capital monopolista, como a Primeira Guerra Mundial (1914-1918) e a crise cíclica de 1929, tiveram desdobramentos na sociedade brasileira como um todo. Abalaram a hegemonia da burguesia agroexportadora, que defendia a vinculação econômica ao capital internacional, e fortaleceram o projeto dos setores burgueses industriais, mobilizados em torno da ideologia do "nacional-desenvolvimentismo". Esses dois projetos se rivalizaram nas décadas seguintes, caracterizando o período que vai de 1930 a 1964, marcado pelo avanço do capital industrial no Brasil.

O nacional-populista, cuja gênese reportava-se a Getúlio Vargas e que agregou setores progressistas da sociedade brasileira, defendia a industrialização do País à base do esforço nacional, sem comprometer a sua soberania. [...]. Por sua vez, o projeto das oligarquias tradicionais, ligadas ao setor agrário exportador, previa o desenvolvimento econômico subordinado à liderança dos Estados Unidos da América e representava setores da elite política desalojada do poder em 1930, especialmente os ligados à economia cafeeira paulista. (BITTAR; BITTAR, 2012, p. 158)

A educação passou por uma série de reformas no período, que foram atravessados por tais conflitos. Ribeiro (2003) indica que persistiu a ampliação da rede escolar, de pessoal docente e de matrículas, embora não tenha se universalizado a escolarização. A porcentagem de crianças em idade escolar que estavam fora da escola era de 54,4\% em 1935 e de 25,8\% em 1955. No caso da educação superior, a situação era mais grave, pois equivalia a 1,3\% da relativa ao ensino elementar, em 1935, e 1,5\% em 1955.

A fim de ilustrar a situação educacional feminina ao final desse período, remete-se aqui à Carvalho (2003, p. 186), ao indicar que “[...] os homens tinham, em 1960, menos de três anos de escolaridade média e as mulheres, menos de dois anos, o que significa que o acesso à escola era em geral muito baixo e ainda pior para as mulheres". Quanto ao Ensino Superior, as matrículas ainda eram restritas, mas demonstravam avanços. "No período 1940-1960 a população do país passou de 41,2 milhões para 70 
milhões (crescimento de 70\%), enquanto que as matrículas no ensino superior triplicaram" (MARTINS, 2002 , p. 5). Esse cenário se aprofunda a partir da década de 1960, levando à inversão do quadro de desigualdade educacional a partir do sexo, o que remete a uma análise mais acurada desse processo.

\section{A expansão das matrículas femininas no ensino superior}

Há um consenso quanto ao fato de que foi só a partir da década de 1960 que as mulheres tiveram maiores chances de ingresso no Ensino Superior (BELTRÃO; ALVES, 2009; SOUZA; SARDENBERG, 2013). A primeira Lei de Diretrizes e Bases da Educação Nacional (LDB), de 1961, Lei $n^{\circ} 4.024$ (BRASIL, 1961), ampara essa constatação, pois representou uma importante medida legal. Com ela "[...] foi garantida equivalência de todos os cursos de grau médio, abrindo a possibilidade para as mulheres que faziam magistério de disputar os vestibulares" (BELTRÃO; ALVES, 2009, p. 130).

Considera-se que essa legislação resultou das próprias exigências do capital produtivo no país, que consolidava sua industrialização e, consequentemente, as típicas formas de organização social urbana. Nesse momento houve a "feminização do trabalho" no Brasil, que reverberou diretamente na sua qualificação escolar.

Com o desenvolvimento do capitalismo em nosso país, a expansão da educação superior passou a ser uma exigência do próprio capital, seja de capacitação da força de trabalho para o atendimento das alterações produtivas, seja para difusão da concepção de mundo burguês sob a imagem de 'política inclusiva'. (LIMA, 2013, p. 6)

No período ditatorial burguês-militar (1964-1985) expandiram-se as vagas nas escolas e no Ensino Superior, tanto para homens como para mulheres, estando em consonância com o avanço do capitalismo, viabilizando-se a "modernização" do país por intermédio de ampla abertura para o capital estrangeiro. Conforme explica Netto (2011, p. 55): “[...] a universidade ganha, para as camadas médias urbanas (que incluem a pequena burguesia tradicional, sem a ela se reduzirem), a centralidade nas suas possibilidades de mobilidade social vertical ascendente".

A expansão observada no Ensino Superior não correspondia, todavia, à demanda efetiva da população, o que gerou pressões estudantis e sociais pela ampliação de vagas. A aprovação da Lei $n^{\circ}$ 5.540/1968, que reformou o Ensino Superior, e da Lei n ${ }^{\circ}$ 5.692/1971, que regulamentou o Ensino de $1^{\circ} \mathrm{e}$ $2^{\circ}$ Graus, atuais ensinos fundamental e médio, adequaram a educação aos imperativos do grande capital.

Foi instituída a profissionalização compulsória no Ensino de $2^{\circ}$ Grau, que "[...] procurava ampliar a matrícula neste grau e dotá-lo de um direcionamento profissionalizante, de cariz terminal" (NETTO, 2011, p. 63, grifos do autor). Buscava-se desse modo conter a demanda pelo acesso à graduação e reduzir os gastos públicos com a educação, resultando em dificuldades de acesso e permanência das classes trabalhadoras à educação, baixos níveis de ensino, altos índices de evasão e repetência, além da desqualificação dos professores das escolas públicas.

A Lei n ${ }^{\circ}$ 5.692/1971 gerou uma efetiva expansão quantitativa de matrículas, “[...] regulamentou o Ensino Supletivo e fixou normativas gerais para o ensino de $1^{\circ}$ e $2^{\circ}$ graus" (ABREU JÚNIOR; PRADO, 2020, p. 100). Ela determinou que os direcionamentos estabelecidos para o Ensino Supletivo tivessem 
como prioridade a formação e o aperfeiçoamento para o mercado de trabalho. Essas iniciativas, mesmo reconhecidas como direito constitucional, eram descontínuas. Abreu Júnior e Prado (2020, p. 103) ressaltam ainda o fato de tais medidas “[...] terem caráter aligeirado e, por vezes, seguirem uma lógica que permanecia assegurando privilégios para os setores mais abastados, que eram historicamente favorecidos".

A visibilidade alcançada pela suplência pode ser compreendida como um processo de “internalização”, que, de acordo com Mészáros (2008, p. 44), tem o objetivo de "[...] assegurar que cada indivíduo adote como suas próprias as metas de reprodução objetivamente possíveis do sistema”. Em outras palavras, um movimento no qual o indivíduo incorpora como suas as metas do capital. No âmbito educacional isso se viabiliza com “[...] a busca por resultados e processos aligeirados, na intenção de legitimar a sua condição na hierarquia social, moldando suas expectativas e conduta ao estipulado pela ordem estabelecida" (ABREU JÚNIOR; PRADO, 2020, p. 101). Essa tem sido a marca do processo que possibilitou o acesso de muitas mulheres à escola, em busca de formação e qualificação para o trabalho, o que se dá muitas vezes de modo precário, permeado pela baixa qualidade.

Netto (2011, p. 63, grifos do autor) identifica na política educacional ditatorial, como “[...] saldo mais significativo", o fato de que promoveu uma “[...] acentuada degradação da rede pública, paralela a uma inédita escalada privatizante". Isso se deu especialmente no Ensino Superior, conduzido pela racionalidade empresarial, processo que se aprofunda na atualidade. Dados apresentados pelo autor sobre a configuração do ensino superior na ditadura demonstram que em 1964 as matrículas no Ensino Superior público representavam 75\% do total, mas, em 1984, correspondiam a apenas $25 \%$. Nesse sentido, Netto (2011, p. 62) afirma que o processo da ditadura “[...] transformou, pela primeira vez na história brasileira, o ensino superior num setor para investimentos capitalistas privados extremamente rentáveis". Para Beltrão e Alves (2009, p. 131), essa expansão geral “[...] favoreceu especialmente o sexo feminino”.

A dissolução da ditadura ocorreu mediante os efeitos da crise capitalista irrompida a partir de meados da década de 1970, cujos reflexos incidiram na sociedade como um todo e no campo educacional, em escala global. A atuação de organismos multilaterais e internacionais na educação se articulou desde então, sendo reveladora da dinâmica global em curso e da apropriação de distintas bandeiras de luta pelo capital, instrumentalizadas para obtenção da ordem social e da reprodução de sua lógica.

Há um receituário mundial recomendado para superação das crises, que envolve a redução nos gastos com as políticas sociais, demarcando o neoliberalismo, estrategicamente articulado para preparar a força de trabalho para o capital. A educação é considerada uma alavanca para o desenvolvimento econômico, para a ascensão social e para a democratização social, de forma utilitarista e acrítica, ignorando-se suas estruturas fundantes.

A nova LDB, Lei no 9.394/1996 (BRASIL, 1996), foi aprovada em meio a esse contexto e sob tais influências, o que impulsionou o processo privatizante para o Ensino Superior. As universidades definiram as formas de ingresso do aluno ao nível superior, o que, para Gisi (2006), tem sido motivo de críticas, pois os processos de seleção têm se constituído em mecanismos de exclusão, que mascaram uma seleção social preexistente. 
Salienta-se que esse desafio não se restringe às mulheres e reside na condição socioeconômica do sujeito, interferindo na sua formação escolar e de vida, adquirida ao longo de sua trajetória. Ademais, para realizar as análises sobre a inserção da mulher no Ensino Superior é insuficiente abordar o viés cultural e social, pois ele não possibilita desvendar o real, limitando-se ao âmbito da aparência dos fenômenos. Isso requer, por conseguinte, desvelar as relações sociais capitalistas historicamente determinadas e, para isso, torna-se importante compreender como o capital funciona. Nos limites deste trabalho, essa tarefa é inviável, restando a possibilidade de sinalizar alguns aspectos dessa relação.

É preciso considerar o acesso de homens e mulheres ao ensino como uma história que se construiu nas entranhas das relações sociais estabelecidas. Lovato (2011) chama a atenção para o fato de que não se trata de uma "guerra" entre homens e mulheres, por isso é preciso cuidado nas análises e nas estratégias de lutas, para não se esvaziar a questão central, que se refere à luta de classes.

Diniz e Queiroz (2019, p. 354) reforçam que “[...] as aproximações que partem das relações sociais e históricas nos ajudam a refletir sobre as desigualdades entre mulheres e homens", sem desconsiderar o fato de que "[...] as expressões desiguais também são importantes para reprodução e expansão do capital". Assim, embora concentrem-se esforços no processo de redução das desigualdades entre homens e mulheres, não se trata de uma rivalidade entre os dois, pois a vida humana como um todo está articulada com as relações sociais voltadas ao lucro, que devem ser analisadas como produto do processo de reprodução do capital mundializado.

A educação da mulher não está imune à essa lógica contraditória que incide na totalidade da vida social e sua defesa vem sendo apropriada pelas entidades multilaterais, de forma estereotipada e economicista. Atribui-se à mulher a responsabilidade pela promoção da saúde, da educação e da renda da família, pela mediação de conflitos comunitários e pela promoção da ordem social, estigmatizando as famílias pobres e imputando as desigualdades sociais e econômicas a elas e aos indivíduos.

“Os direitos são mercantilizados e transformados em oportunidades econômicas e sociais de trabalho informal para geração de renda nessa lógica difundida por estes órgãos e entidades [...]” (LEMOS et al., 2015, p. 203), evidenciando que não há neutralidade nas medidas educacionais em curso, eivadas de um viés economicista. O Brasil é diretamente afetado por tais organismos multilaterais, por intermédio de avaliações, regulações e diretrizes educacionais deles emanadas, sendo esse processo acompanhado de perto em sua evolução e nos projetos desenvolvidos.

No relatório Education at a Glance 2019 (OECD, 2019), divulgado pela Organização para a Cooperação e Desenvolvimento Econômico (OCDE), constata-se o avanço global das mulheres na Educação Superior. "Enquanto 18\% dos homens brasileiros de 25 a 34 anos têm ensino superior, essa porcentagem sobe para $25 \%$ entre as mulheres da mesma faixa etária (mesmo assim, muito abaixo das médias da OCDE, de 38\% para homens e 51\% para mulheres, segundo dados de 2018)" (IDOETA, 2019, p. 1).

As características sobre a inserção no Ensino Superior brasileiro, segundo o Censo da Educação Superior de 2019 (INEP, 2020), confirmam que a presença é majoritária das mulheres, tanto na modalidade presencial, quanto no ensino a distância, e as matrículas se dão em sua maioria no âmbito 
privado. Destaca-se que na modalidade a distância predomina a inserção nos cursos de licenciaturas. No Ensino Médio, a taxa de conclusão também é mais elevada entre elas.

Perissé e Loschi (2019), com base na Pesquisa Nacional por Amostra de Domicílios (PNAD) Contínua, do $4^{\circ}$ trimestre de 2018, constataram que, das mais de 6,2 milhões de pessoas empregadas, 4,5 milhões $(94,1 \%)$ são mulheres. Sobre as escolhas profissionais, ou seja, quais as áreas mais escolhidas pelo público feminino, o Gráfico 1 retrata o perfil atual, por sexo:

Figura 1 - Ocupação das mulheres $-4^{\circ}$ trimestre/2018

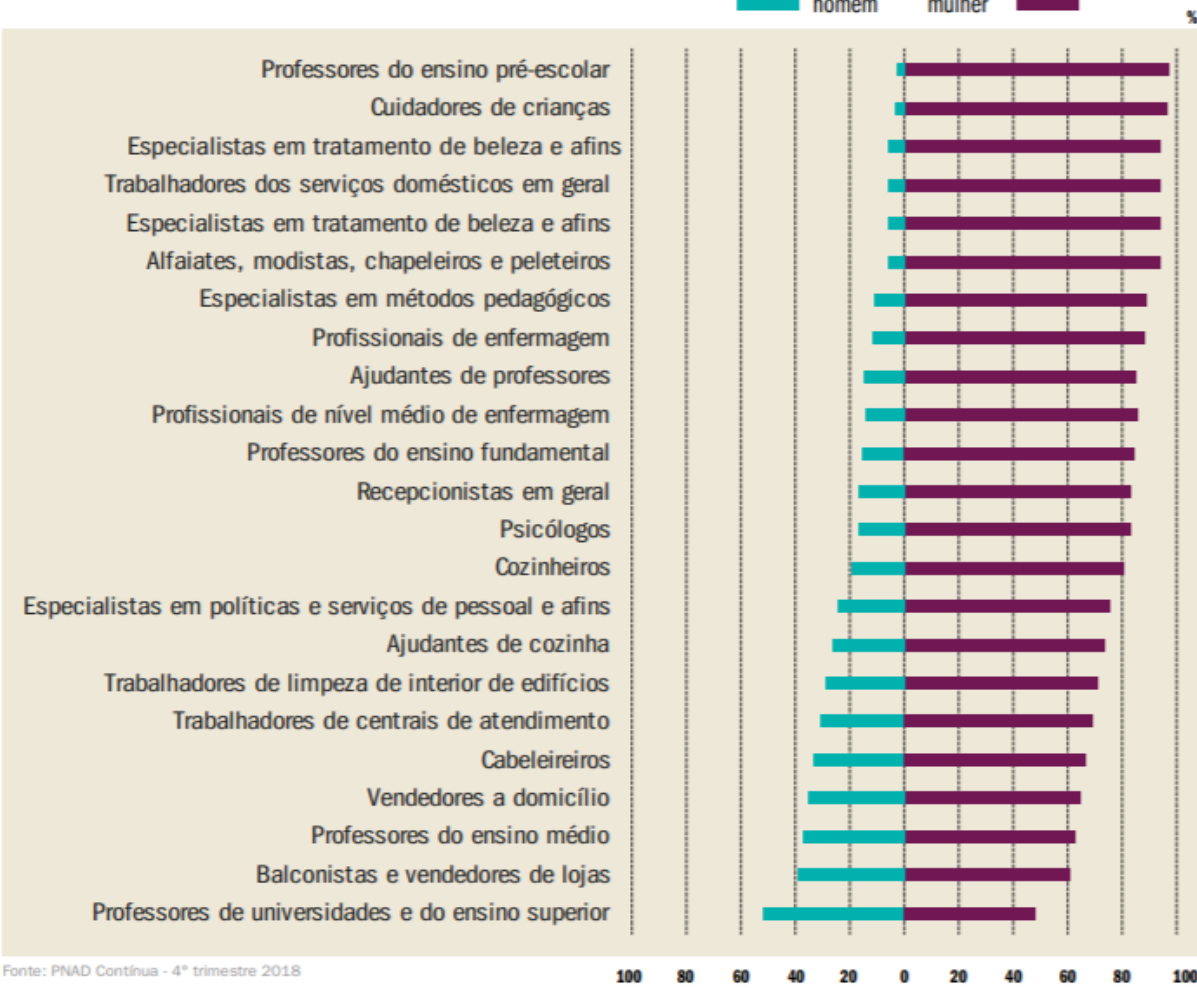

Fonte: Perissé e Loschi (2019, p. 22).

Fica demonstrado na Figura 1 que as mulheres são inseridas em sua maioria nas profissões de Professores, Profissionais da Enfermagem, Psicólogas, entre outras, o que afeta também suas escolhas para o Ensino Superior. Os dados do $4^{\circ}$ trimestre de 2017 revelavam conclusões próximas.

A PNAD Contínua mostra, também, que a participação das mulheres supera a dos homens em algumas profissões culturalmente identificadas como 'femininas' e associadas a menores salários. A maior disparidade é encontrada na categoria dos empregados domésticos, na qual $92,3 \%$ são mulheres. Mas elas também predominam no magistério, nas enfermarias e na assistência social. Nesse sentido, no setor da administração pública, defesa e seguridade social, educação, saúde e serviços sociais, a participação das mulheres $(25,2 \%)$ era bem maior que a dos homens $(10,9 \%)$. (SARAIVA; BELLO; RENAUX, 2018, p. 1)

Ávila e Portes (2009) coadunam com essa interpretação e inferem que no Ensino Superior permaneceram desigualdades no final do século XX, apesar de ter se ampliado o acesso. As mulheres permanecem adentrando em determinados cursos específicos, sob influência de elementos ideológicos e sociais que são introjetados na subjetividade dos indivíduos. 
Segundo Queiroz (2000), mesmo com a grande inserção das mulheres no ensino superior brasileiro, a 'ideologia da vocação', que por meio de instituições e práticas sociais, faz-se introjetada e interiorizada nos sujeitos femininos e masculinos, ainda se configurava uma realidade na última década do século XX, levando à 'guetização' das carreiras. (ÁVILA; PORTES, 2009, p. 92)

Assim, homens e mulheres aprenderiam quais deveriam ser suas posições perante a sociedade, naturalizando-as e constituindo o que se chama de "ideologia da vocação", que foi historicamente constituída. Isso se daria inclusive na própria formação:

[...] as preferências quanto à escolha dos cursos foram se construindo ao longo do processo de escolarização dos sujeitos femininos e masculinos, dando origem a áreas demarcadas como mais 'femininas', como a área das ciências humanas e a maior parte dos cursos da saúde, ou mais 'masculinas', como aqueles da área das ciências exatas e carreiras tecnológicas. (ÁVILA; PORTES, 2009, p. 95)

$\mathrm{Na}$ mesma linha de análise, também identificaram posições pautadas na relação da divisão sexual do trabalho e detectaram uma seleção já no processo de escolha de certas áreas de estudo, o que ficaria perceptível nas escolhas de carreiras consideradas de maior prestígio e remuneração. As áreas de estudo do público masculino seriam aquelas "[...] de formação profissional tidas como mais qualificadas, que habilitariam os concluintes para postos de trabalho de maior prestígio e remuneração, enquanto as áreas mais 'femininas' seriam as menos qualificadas, perpetuando a discriminação de gênero no mercado de trabalho" (ÁVILA; PORTES, 2009, p. 96, grifos dos autores).

Ao se analisar a posição da mulher no atual estágio de desenvolvimento do país, as estatísticas revelam que elas possuem condições suficientes de escolarização, tornando-as capazes de competir em condições de igualdade, em qualquer curso ou profissão que escolherem. Entretanto, aspectos como a maternidade ainda são mobilizados como justificativa para inviabilizar sua inserção em condições de igualdade. Ressalta-se que essa justificativa é utilizada tanto no âmbito do mercado, para a não contratação de mulheres, como também em estudos relacionados ao enfrentamento das desigualdades de gênero. Alega-se que o mercado não as contrata por serem mulheres e estarem imbuídas biologicamente da condição de maternidade.

Salienta-se a necessidade de análises mais profundas dessa questão, vinculadas à reprodução do capital. Isso porque há mudanças nos padrões sociais atribuídos ao papel da mulher na sociedade, intensificadas durante os movimentos feministas dos anos de 1970. Alterou-se sua presença nos espaços públicos e transformou-se a população brasileira e de suas famílias. Segundo Bruschini e Lombardi (2016, p. 162), “[...] a taxa de fecundidade caiu de 5,8 filhos, em 1970, para 2,3 filhos em 1999”. Também já se vislumbram metamorfoses em curso na paternidade e nas funções do homem nas tarefas da família.

Quanto à opção de formação feminina, no Resumo Técnico do Censo da Educação Superior de 2019 (INEP, 2021c) são apresentados os 20 maiores cursos, segundo o número de matrículas realizadas em cursos de graduação, e seus respectivos percentuais de participação por sexo. Observa-se que entre os 20 maiores cursos, de acordo com o número de matrículas, 14 têm maior presença feminina e em seis, a presença masculina é maior. Os cursos em que predominam as mulheres são: "Pedagogia (92,1\%), Serviço social (89,6\%), Enfermagem (83,7\%), Nutrição (83,3\%), Psicologia (79,5\%), Gestão de pessoas $(78,0 \%)$, 
Fisioterapia (77,3\%), Odontologia (71,5\%), Farmácia (70,9\%), Arquitetura e Urbanismo (66,6\%), Medicina (59,7\%), Contabilidade (56,2\%), Direito (55,2\%) e Administração (54,5\%)" (INEP, 2021c, p. 36).

Já os seis cursos com predomínio masculino, segundo o número de matrículas, são: "Engenharia mecânica (89,9\%), Sistemas de informação (86,0\%), Engenharia Civil (69,8\%), Engenharia de produção (66,3\%), Educação física (64,9\%) e Educação física formação de professor (60,8\%)” (INEP, 2021c, p. 36). Mesmo nesses cursos, já é possível identificar um avanço de matrículas femininas, apontando uma tendência à redução dessa desigualdade.

No que se refere à presença feminina como profissional da educação, segundo o Censo Escolar de 2020: "Em todas as etapas de ensino da educação básica, as mulheres são maioria (96,4\% das mulheres na Educação Infantil; 88,1\% nos anos iniciais no Ensino Fundamental; 66,8\% nos anos finais e 57,8\% no ensino médio)" (INEP, 2021a, p. 1).

Uma análise mais profunda, para além das questões culturais e subjetivas, novamente faz-se necessária. É preciso levar em consideração a intencionalidade desse processo, pois não se constitui a partir de uma vontade individual das mulheres, suas escolhas também são determinadas.

Em relação ao perfil socioeconômico da mulher no Ensino Superior, por exemplo, o Relatório Técnico no 01/2014 apresentou a Escolha de Carreiras em função do nível socioeconômico, com base no Enade de 2004 a 2012. Segundo esse relatório: “Os mais baixos índices de afluência socioeconômica correspondem às carreiras ligadas à educação infantil e dos anos iniciais do Ensino Fundamental (Normal Superior e Pedagogia)" (BELTRÃO; MANDARINO, 2014, p. 48).

Amparada por uma vasta análise de dados empíricos recentes e também mundiais, relativos ao trabalho, à educação, aos salários das mulheres, dentre outros, Calado (2020) constatou que a necessidade de reprodução do capital acarretou o espraiamento da proletarização, sem preconceito de sexo e raça, resultando em uma tendência crescente à aproximação de salários de homens e mulheres, principalmente a partir dos anos 2000. A autora supracitada identificou também que as mulheres aumentam a participação na renda familiar, inserem-se cada vez mais em trabalhos antes tido como masculinos e também no mercado de trabalho formal, em correspondência com a melhoria de sua qualificação.

Quanto à jornada de trabalho semanal feminina, Calado (2020) constatou que ela é, em média, inferior. Provavelmente a maternidade seja um fator significativo para tal condição, mas o fato é que o tempo de trabalho repercute na diferença salarial, exigindo que se ampliem os estudos para além da questão do sexo. Torna-se importante, por conseguinte, levar em conta os determinantes econômicos do capital.

No caso da ampliação da presença das mulheres no Ensino Superior brasileiro, por conseguinte, não há como ignorar que isso coincide diretamente com o fortalecimento da rede privada, como já destacado neste estudo por Netto (2011). No contexto atual, marcado pela crise do capital, uma das investidas para sua superação tem sido o processo de intensificação da mercadorização da educação pública e gratuita, por meio do ensino a distância. Isso vem sendo denunciado com frequência:

[...] pautados nos dados da realidade, é possível identificar a tendência do capital de empresas da educação por meio da educação à distância e do ensino remoto. Ao 
mesmo tempo, é possível apontar para a tendência do movimento de isenção do Estado em oferecer educação pública e gratuita. Ensino à distância por meio da oferta privada parece ser o caminho que o capital tem traçado, especificamente, para a saída da atual crise. (TUMOLO; OLIVEIRA; BUENO, 2021, p. 134)

Esse movimento insaciável tem resultado na subsunção da vida social como um todo ao capital, afetando as distintas esferas da subjetividade humana. Ademais, outro aspecto a considerar, é que o próprio movimento do capital mundial se apropriou ideologicamente das lutas feministas por educação, convertendo-as em solução para problemas estruturais, conforme disseminado pelos organismos internacionais:

[...] a chamada capacitação das mulheres ganha estatuto de prioridade na agenda política desses órgãos - UNESCO e UNICEF. Para ambos, grande parte da problemática da violação de direitos, da violência e da pobreza seria resolvida com formação. Os técnicos prescrevem a importância da mãe se fundamentar na ciência para salvaguardar a tarefa educacional dos filhos em prol da promoção do desenvolvimento infantil, publicando materiais, organizando congressos e ampliando a rede de controle das famílias na proteção das crianças e adolescentes. (LEMOS et al., 2015, p. 125)

A partir das análises desenvolvidas, evidencia-se a validade das lutas das mulheres no campo da igualdade de inserção, entretanto, não dá para desconsiderar que tais lutas, isoladas, não são suficientes e podem até se converter em benefício para a exploração do capital. É o caso da ideologia do empoderamento, que se acaba aliando a conceitos como empreendedorismo e cidadania ativa, por exemplo.

Resulta num tipo de desenraizamento de classe pela ilusão de que através do empoderamento passa a ser possível à trabalhadora assumir as rédeas de seu trabalho, ser sua própria patroa, ao mesmo tempo, que se mantêm práticas de desigualdade, já que os efetivos responsáveis pela desigualdade de acesso ao poder real permanecem intocados. (CALADO, 2020, p. 214)

Isso explica em grande parte o fato dos organismos internacionais se apropriarem das bandeiras identitárias, mistificando-as. Nesse sentido é preciso considerar a realidade como parte de um projeto determinado, pois, conforme explica Lemos et al. (2015, p. 209), a educação formal de mulheres também possui uma intencionalidade, “[...] para que elas saibam realizar o planejamento familiar, cuidar dos filhos e da casa, de acordo com os princípios higienistas".

Entende-se, por conseguinte, que a educação e a liberdade femininas estão condicionadas à emancipação da humanidade, à sua libertação de relações sociais desiguais, radicadas na propriedade privada, o que não ocorrerá por uma simples alteração das consciências, muito menos individuais. No sentido oposto ao idealismo, a concepção de história aqui adotada tem o objetivo,

[...] não de explicar a práxis partindo da ideia, mas de explicar as formações ideais a partir da práxis material e chegar, com isso, ao resultado de que todas as formas e [todos os] produtos da consciência não podem ser dissolvidos por obra da crítica espiritual, por sua dissolução na 'autoconsciência' ou sua transformação em 'fantasma', 'espectro', 'visões’ etc., mas apenas pela demolição prática das relações sociais reais [realen] de onde provêm essas enganações idealistas; não é a crítica, mas a revolução a força motriz da história e também da religião, da filosofia e de toda forma de teoria. (MARX; ENGELS, 2007, p. 43)

Mediante o exposto, não dá para prescindir da consideração dos determinantes estruturais do capital que se fazem presentes, tanto na educação da mulher quanto em sua condição socioeconômica. 
Tumolo, Oliveira e Bueno (2021) explicam que, com o advento da classe burguesa, novas relações sociais se estabelecem, a partir de outra base material. A transformação da força de trabalho em mercadoria assegurou a consolidação da classe capitalista. A partir disso, independente de vontades pessoais, as relações humanas passam a ser desenvolvidas sob o domínio das relações de produção capitalistas.

Considerar esses fatores estruturais não significa abandonar as lutas femininas, mas sim ampliálas e fortalecê-las, articulando-as com a perspectiva de classe. Na educação, o movimento do real vem apontando que esse processo do capital, de 'abocanhar' a educação pública e gratuita, não é uma questão que afeta apenas as mulheres, mas terá consequências para o conjunto da classe trabalhadora.

\section{Considerações Finais}

As mulheres hoje predominam no Ensino Superior, mas sua efetiva entrada foi somente após a década de 1960, concomitante ao momento em que se expandiu o Ensino Superior privado no Brasil, na esteira das exigências do modo de produção capitalista.

Ao verificar a sua condição profissional atual, especificamente, constata-se que, mesmo possuindo maior escolaridade, as mulheres ainda recebem menos que os homens em relação a uma mesma atividade. Vários estudos atribuem o fato de a mulher não ter o mesmo reconhecimento profissional que o dos homens a fatores sociais e culturais, que ocasionaram também sua predominância em cursos considerados como "tipicamente femininos", de menor prestígio e baixa remuneração salarial.

Destaca-se que é importante vislumbrar a condição feminina ao longo da história, suas lutas e dificuldades para receber educação escolarizada, entretanto, esses aspectos ficam restritos às aparências dos fenômenos se não se levar em conta as relações reais em que se dá a reprodução da existência humana. Infere-se que os elementos econômicos, ou ainda de forma mais complexa, as análises das relações sociais capitalistas, são essenciais para a compreensão da inserção das mulheres nas escolas e no nível superior, bem como sua condição enquanto integrante da classe trabalhadora.

Os dados reunidos neste estudo demonstram que o avanço da escolarização feminina e em geral esteve diretamente associado à expansão do capital mundial. Este implicou na urbanização e na universalização das relações capitalistas de exploração, incluindo o trabalho feminino. Seu acesso ao Ensino Superior, por sua vez, foi intensificado a partir do aprofundamento da industrialização e da privatização desse ensino no Brasil, sinalizando para a necessidade de adensar a análise dessa questão a partir da relação social do capital.

A humanidade como um todo é afetada pela desigualdade social e econômica, tendo impactos na escolarização e no Ensino Superior, o que demanda uma luta mais ampla da classe trabalhadora para a superação dos fundamentos dessa relação social. Diante disso, torna-se necessário reafirmar que a luta das mulheres está ligada à luta mais ampla, pela criação de uma relação social que beneficie a todos, em condições mais dignas e igualitárias. 


\section{Referências:}

ABREU JÚNIOR, Jupter Martins de; PRADO, Helen Wanderley do. A educação de jovens e adultos no Brasil: entre trajetórias descontínuas e a expectativa do direito. Dialogia, São Paulo, n. 35, p. 93-106, maio/ago. 2020. Disponível em: https://periodicos.uninove.br/dialogia/article/view/16910. Acesso em: 15 nov. 2021.

ALMEIDA, Jane Soares de. Mulher e educação: a paixão pelo possível. São Paulo: Editora Unesp, 1998.

ARANHA, Maria Lúcia de Arruda. História da educação e da pedagogia: geral e Brasil. 3. ed. rev. e ampl. São Paulo: Moderna, 2006.

ÁVILA, Rebeca Contrera; PORTES, Écio Antônio. Notas sobre a mulher contemporânea no ensino superior. Mal-Estar e Sociedade, ano II, n. 2, Barbacena, p. 91-106, jun. 2009. Disponível em: https://revista.uemg.br/index.php/gtic-malestar/article/view/13. Acesso em: 30 nov. 2020.

BELTRÃO, Kaizô Iwakami; ALVES, José Eustáquio Diniz. A reversão do hiato de gênero na educação brasileira no século XX. Cadernos de Pesquisa, v. 39, n. 136, p. 125-156, jan./abr. 2009. Disponível em: http://publicacoes.fcc.org.br/ojs/index.php/cp/article/view/277. Acesso em: 17 jan. 2021.

BELTRÃO, Kaizô Iwakami; MANDARINO, Mônica Cerbella Freire. Escolhas de carreiras em função do nível socioeconômico: Enade 2004 a 2012. Relatório Técnico 2014. Rio de Janeiro: Fundação Cesgranrio, 2014. Disponível em:

https://www.cesgranrio.org.br/pdf/Enade/RELATORIO\%20TECNICO\%20(2004-2012)\%20-

$\% 20$ estudo\%20ENADE\%2015-10-2014\%20-

$\% 20$ Vers $\%$ C3\%A3o $\% 20$ final_Publica $\%$ C3\%A7\%CC3\%A3o $\% 20$ meio $\% 20$ magn $\% C 3 \% A 9$ tico_com $\% 20$ seg uran\%C3\%A7a.pdf. Acesso em: 08 nov. 2020.

BITTAR, Marisa; BITTAR, Mariluce. História da educação no Brasil: a escola pública no processo de democratização da sociedade. Acta Scientiarum, Maringá, v. 34, p. 157-168, jul./ dez 2012.

https://doi.org/10.4025/actascieduc.v34i2.17497

BRASIL. Legislação Informatizada, Lei no 4.024 de 20 de dezembro de 1961. Publicação Original. Câmara dos deputados. Brasília, DF, 1961. Disponível em:

https://www2.camara.leg.br/legin/fed/lei/1960-1969/lei-4024-20-dezembro-1961-353722-

publicacaooriginal-1-pl.html. Acesso em: 05 ago. 2021.

BRASIL. Legislação Informatizada, Lei no 9.394, de 20 de dezembro de 1996. Publicação Original. Câmara dos deputados. Brasília, DF, 1996. Disponível em:

https://www2.camara.leg.br/legin/fed/lei/1996/lei-9394-20-dezembro-1996-362578-publicacaooriginal1-pl.html. Acesso em: 05 ago. 2021.

BRUSCHINI, Cristina; LOMBARDI, Maria Rosa. Instruídas e trabalhadeiras: trabalho feminino no final do século XX. Cadernos Pagu, Campinas, SP, n. 17-18, p. 157-196, 2016. Disponível em:

https://periodicos.sbu.unicamp.br/ojs/index.php/cadpagu/article/view/8644559. Acesso em: 12 mar. 2021.

CALADO, Joana das Neves. A classe trabalhadora não tem sexo nem gênero: crítica da "ordem patriarcal de gênero" de Heleieth Saffioti. 2020. Orientador: Vania Maria Manfroi. 2020. $294 \mathrm{f}$. Tese (Doutorado em Serviço Social) - Universidade Federal de Santa Catarina, Florianópolis, 2020. Disponível em: https://repositorio.ufsc.br/handle/123456789/216483. Acesso em: 10 mai. 2021.

CARVALHO, Marília Pinto de. Sucesso e fracasso escolar: uma questão de gênero. Educação e Pesquisa, São Paulo, v. 29, n. 1, p. 185-193, jan./jun. 2003. Disponível em: https://www.scielo.br/j/ep/a/whzMRVSVmcVCgfY9CkfMt4n/?lang=pt\&format=pdf. Acesso em: 10 nov. 2020.

DIEESE. A inserção das mulheres no mercado de trabalho. Outras publicações, 2021. Disponível em: https://www.dieese.org.br/outraspublicacoes/2021/graficosMulheresBrasilRegioes2021.pdf. Acesso em: 12 ago. 2021.

DINIZ, Maria Ilidiana; QUEIROZ, Fernanda Marques de. Assédio sexual contra mulheres no contexto da crise estrutural do capital. In: SALVADOR, Evilasio; BEHRING, Elaine; LIMA, Rita de Lourdes de. 
(Orgs.). Crise do capital e fundo público: implicações para o trabalho e a política social. 1. ed. São Paulo: Cortez, 2019, v. 1, p. 343-363.

FERRARO, Alceu Ravanello. Escolarização no Brasil: articulando as perspectivas de gênero, raça e classe social. Educação e Pesquisa. São Paulo, v. 36, n. 2, p. 505-526, maio/ago. 2010. https://doi.org/10.1590/S1517-97022010000200006

GISI, Maria Lourdes. A Educação Superior no Brasil e o caráter de desigualdade do acesso e da permanência. Revista Diálogo Educacional. Curitiba, v. 6, n. 17, p. 97-112, jan./abr. 2006. http://dx.doi.org/10.7213/rde.v6i17.6740

IDOETA, Paula Adamo. Mulheres são maioria nas universidades brasileiras, mas têm mais dificuldades em encontrar emprego. BBC News Brasil, 10 set. 2019. Disponível em: https://www.bbc.com/portuguese/geral-49639664. Acesso em: 10 ago. 2021.

INEP. Escolar, Censo 2020. Inep divulga dados da $1^{\text {a }}$ etapa do Censo Escolar 2020. 2021 a. Disponível em: https://www.gov.br/inep/pt-br/assuntos/noticias/censo-escolar/inep-divulga-dados-da1a-etapa-do-censo-escolar-2020. Acesso em: 15 jul. 2021.

INEP. Institucional. Mulheres predominam em estudos, pesquisas e exames. Brasília: INEP, mar. 2021b. Disponível em: https://www.gov.br/inep/pt-br/assuntos/noticias/institucional/mulherespredominam-em-estudos-pesquisas-e-exames-educacionais. Acesso em: 17 ago. 2021.

INEP. Notas Estatísticas 2019. Censo da Educação Superior 2019. Brasília, INEP, 2020. Disponível em:

https://download.inep.gov.br/educacao_superior/censo_superior/documentos/2020/Notas_Estatisticas _Censo_da_Educacao_Superior_2019.pdf. Acesso em: 10 ago. 2021.

INEP. Resumo Técnico do Censo da Educação Superior 2019. Brasília: INEP, 2021c. Disponível em: https://download.inep.gov.br/publicacoes/institucionais/estatisticas_e_indicadores/resumo_tecnico_cen so_da_educacao_superior_2019.pdf. Acesso em: 23 jul. 2021.

LEMOS, Flávia Cristina Silveira et al. Biopolítica, gênero e organismos internacionais: mercado dos direitos das mulheres. Revista de Psicologia, v. 27, n. 3, p. 203-210, set./dez. 2015.

https://doi.org/10.1590/1984-0292/1478

LIMA, Katia. Expansão da educação superior brasileira na primeira década do novo século. In: PEREIRA, Larissa Dahemer; ALMEIDA, Ney Luiz Teixeira de (Orgs.). Serviço Social e Educação. Rio de Janeiro: Lumen Juris, 2013, p. 1-26.

LOVATO. Angélica. O poder do macho: um encontro com Heleieth Saffioti. Lutas Sociais, São Paulo, n. 27, p. 110-118, 2. sem. 2011. https://doi.org/10.23925/ls.v0i27.18736

MARTINS, Antonio Carlos Pereira. Ensino superior no Brasil: da descoberta aos dias atuais. Acta Cirúrgica Brasileira, v. 17, supl. 3, p. 04-06, 2002. https://doi.org/10.1590/S0102-86502002000900001

MARX, Karl; ENGELS, Friedrich. A ideologia alemã. São Paulo: Boitempo, 2007.

MARX, Karl. O Capital: crítica da economia política. v. II. 2. ed. São Paulo: Nova Cultural, 1985.

MÉSZÁROS, István. A educação para além do capital. São Paulo: Boitempo, 2008.

NETTO. José Paulo. Ditadura e Serviço Social: uma análise do Serviço Social no Brasil pós-64. 16. ed. São Paulo: Cortez, 2011.

NEVES, Lúcia Maria Wanderley; PRONKO, Marcela Alejandra. Configuração histórica e mudanças da formação para o trabalho complexo no Brasil contemporâneo. Rio de Janeiro: EPSJV, 2008.

OECD. Education at a Glance 2019. OECD Indicators. Paris: OECD Publishing, 2019. https://doi.org/10.1787/f8d7880d-en

PENA, Maria Valéria Junho. Mulheres e Trabalhadoras: presença feminina na constituição do sistema fabril. Rio de Janeiro: Paz e Terra, 1981.

PERISSÉ, Camille; LOSCHI, Marília. Trabalho "de mulher". Retratos, a revista do IBGE, n. 17, jul./ago. 2019. Disponível em: 
https://agenciadenoticias.ibge.gov.br/media/com_mediaibge/arquivos/b06abac34a360666981b4b866217 76f2.pdf. Acesso em: 02 ago. 2021.

RIBEIRO, Maria Luiza Santos. História da educação brasileira: a organização escolar. 18. ed. rev. ampl. Campinas, SP: Autores Associados, 2003.

RITT, Caroline Folckikc. A conquista da educação pelas mulheres na história do Brasil, a violência doméstica praticada contra a mulher e a aplicação do art. 41 da Lei Maria da Penha, para a punição do agressor da violência de gênero. Revista do Curso de Direito da FSG, Caxias do Sul, ano 6, n. 12, p. 41 53, jul./dez. 2012. Disponível em: https://silo.tips/download/caroline-fockink-ritt. Acesso em: 20 jul. 2021.

SARAIVA, Adriana; BELLO, Luiz; RENAUX, Pedro. No Dia da Mulher, estatísticas sobre trabalho mostram desigualdade. Agência IBGE notícias, 08 mar. 2018. Disponível em:

https://agenciadenoticias.ibge.gov.br/agencia-noticias/2012-agencia-de-noticias/noticias/20287-no-diada-mulher-estatisticas-sobre-trabalho-mostram-desigualdade. Acesso em: 02 ago. 2021.

SILVA, Erineusa Maria da. As relações de gênero no magistério: a imagem da feminização. Vitória: Edufes, 2002.

SOUZA, Regis Glauciane Santos de; SARDENBERG, Cecília Maria B. Visibilizando a mulher no espaço público: a presença das mulheres nas universidades. In: SEMINÁRIO INTERNACIONAL FAZENDO GÊNERO, 10 ed., 2013. Florianópolis. Anais... Florianópolis: UFSC, p. 1-12. Disponível em: http://www.fg2013.wwc2017.eventos.dype.com.br/resources/anais/20/1381429366_ARQUIVO_Regis GlaucianeSantosdeSouza.pdf. Acesso em: 20 jul. 2021.

TUMOLO, Paulo Sérgio; OLIVEIRA, André Ricardo; BUENO, Juliane Zacharias. Da educação pública à educação privada: os rumos do ensino superior no Brasil. Germinal: Marxismo e Educação em Debate, Salvador, v. 13, n. 1, p. 119-137, abr. 2021. https://doi.org/10.9771/gmed.v13i1.43599

\begin{abstract}
Notas
${ }^{1}$ Licenciada em Pedagogia (UNESPAR), Campus Paranavaí. Mestranda do Programa de Pós-Graduação em Ensino: Formação Docente Interdisciplinar (PPIFOR), na UNESPAR, Campus Paranavaí. Integrante do Grupo de Estudos e Pesquisas Trabalho e Educação na Sociabilidade do Capital (GEPTESC): http://dgp.cnpq.br/dgp/espelhogrupo/271903. Lattes: http://lattes.cnpq.br/3134167567598788. $\quad$ ORCID: $\quad$ https://orcid.org/0000-0003-3670-3595. $\quad$ E-mail: anacristinafurtado0304@hotmail.com.

2 Doutora em Educação (UFSC). Professora do Colegiado de Pedagogia e do Programa de Pós-Graduação em Ensino: Formação Docente Interdisciplinar (PPIFOR), na Universidade Estadual do Paraná (UNESPAR), Campus Paranavaí. Líder do Grupo de Estudos e Pesquisas Trabalho e Educação da Sociabilidade e Capital (GEPTESC): http://dgp.cnpq.br/dgp/espelhogrupo/271903. Pesquisadora do Grupo de Estudos Capital, Trabalho e Educação (GECATE): http://dgp.cnpq.br/dgp/espelhogrupo/52985. Lattes: $\underline{\text { http://lattes.cnpq.br/6325209425358903. }}$ ORCID: https://orcid.org/0000-0003-0569-7225. E-mail: neidegafa@hotmail.com.

${ }_{3}^{3}$ Mestre em Serviço Social e Política Social (UEL). Doutoranda em Serviço Social (UFSC). Professora do Colegiado de Serviço Social da Universidade Estadual do Paraná (UNESPAR), Campus Paranavaí. Vice-Líder do Grupo de Estudos e Pesquisas Trabalho e Educação na Sociabilidade do Capital (GEPTESC): http://dgp.cnpq.br/dgp/espelhogrupo/271903. Lattes: http://lattes.cnpq.br/1012388941501759. $\quad$ ORCID: $\quad \underline{\text { https://orcid.org/0000-0002-5410-2585. }}$ E-mail: priscilasemzezem@hotmail.com.
\end{abstract}

